\title{
TeOría de LA NOVELA Y DEL CUENTO: un homenaje a Mariano Baquero Goyanes
}

\author{
Patricia Teresa López Ruiz \\ Universidad de Murcia
}

El proyecto de investigación Genus Novel, dirigido por el profesor de la Universidad de Zaragoza Luis Beltrán Almería e integrado por profesores de universidades nacionales y extranjeras, publica una obra que se podría calificar como sugerente y esperanzadora, actual y necesaria ${ }^{1}$. Coordinado por Ana Luisa Baquero Escudero y Francisco Vicente Gómez, y publicado por la editorial Visor, este libro aúna los estudios presentados en el I Simposio Internacional Mariano Baquero Goyanes. Teoría de la novela y el cuento, celebrado en la Universidad de Murcia, en noviembre de 2019. Este volumen en torno a la obra de Mariano Baquero se constituye, junto con las publicaciones de La teoría de la novela de Mijail Bajtin o La novela. Destinos de la teoría de la novela de György Lukác, como una de las recientes y más relevantes aportaciones a la teoría contemporánea de la novela que viene realizando este grupo de investigación durante los últimos tres años.

Desde el título, Mariano Baquero Goyanes. Teoría de la novela y del cuento, se aprecia la rica heterogeneidad de los trabajos que se incorporan. Además de dar cuenta de la diversa y abultada nómina de estudios que en relación con estas formas narrativas realizó el antiguo catedrático de la Universidad de Murcia, bajo este encabezado se recogen aportaciones que demuestran la fructífera aplicación de los mismos en el análisis de obras contemporáneas y que, por tanto, manifiestan la actualidad de sus ideas literarias. Está constituido el libro por dieciséis trabajos, enmarcados -al inicio- por unas palabras preliminares que bosquejan la brillante carrera investigadora del autor y una presentación de Antonio García Berrio, a modo de laudatio, en la que se respira la infinita deuda que este renombrado investigador posee con aquel a quien considera su principal maestro, Baquero Goyanes. A su vez, a esta obra pone su broche final una curiosa y emocionante muestra de la correspondencia que el investigador mantuvo con varios y grandes escritores e

\footnotetext{
${ }^{1}$ Ana Luisa Baquero Escudero y Francisco Vicente Gómez (coords.), Mariano Baquero Goyanes. Teoría de la novela y del cuento, Madrid, Visor, 2020.
} 
investigadores de su época, desde el mismísimo Azorín hasta Carlos Bousoño, desde Dámaso Alonso hasta Medardo Fraile, pasando por otros como Francisco Ayala o Vicente Aleixandre.

Estos dieciséis trabajos aparecen divididos en tres bloques: «El cuento. Propuestas y análisis», «La novela. Teoría y crítica» y «La enseñanza de la literatura», como homenaje a aquel que dio sus primeros pasos con una tesis sobre el cuento español en el siglo XIX (género que nunca abandonaría), manifestó un sempiterno interés por todo lo novelesco y nunca se olvidó de buscar el tamiz con que acercar a las nuevas generaciones sus avances y pasión por la literatura. Sin embargo, todos los estudios se encuentran aunados por un sentimiento común, el de una obra que ilumina conceptos, acerca y compara lo distante, dilata puntos de vista o plantea grietas mientras arroja una indisoluble fusión entre lo histórico, teórico y crítico, inspiradora y moderna, que no ha de perderse.

De esta manera, el primer bloque se abre con el propósito de Borja Rodríguez Gutiérrez de establecer con el catedrático de Murcia ese diálogo sobre los cuentos populares y dramáticos del Romanticismo español que el tiempo y la vida les vetó. Si este se refiere a la obra El cuento español en el siglo XIX, Ezpeleta Aguilar, por su parte, se centra en la que -dentro de la producción de Baquero-podría considerarse una continuación de la ya mencionada El cuento español. Del Romanticismo al Realismo. Al comparar ambos libros, Ezpeleta Aguilar destaca la reivindicación que el crítico realiza de un autor de gran interés -dentro del material cuentístico para niños- como Manuel Polo y Peyrón, sobre el que, sin embargo, la crítica actual «ha mantenido un discreto silencio» (p.53). Algo similar a esto señala Palomo Alepuz al presentar la acertada aproximación que Baquero realizó de la obra mironiana en la línea renovadora de la literatura occidental contemporánea, en una época en la que la visión de la novela desde un punto de vista más tradicional conducía al rechazo de las obras del levantino. Sin duda, estos tres trabajos ofrecen un acercamiento a algunos sólidos monográficos y lúcidos artículos de Baquero; sin embargo, fueron diversos los tipos de discurso de los que este se sirvió para exponer sus ideas. Prueba de ello es el excelente prólogo que escribe a la antología de cuentos clarinianos, acercándose a su análisis desde el prisma de la ternura, y sobre el que Abraham Esteve focaliza su estudio. En este trabajo, se evidencia el pionero papel que Baquero tuvo en la recuperación de la obra narrativa clariniana. Así, sus teorías acerca de la función que la lectura debe desempeñar quedan enmarcadas entre el concepto de inmersión de Teodoro Lipps y El acto de leer de Wolfgang Iser, mostrando la anticipación del investigador a algunas de las propuestas de este último. Por su parte, Raquel Gutiérrez Sebastián parte de la relación propuesta por Baquero entre el cuento y la poesía lírica, así como de los conceptos de «condensación», «instantaneidad» 
Teoría de la novela y del cuento: un homenaje a Mariano Baquero Goyanes

y «capacidad emocional y estética» para abordar el estudio de los cuentos que conforman Los niños tontos de Ana María Matute, demostrando a la luz de esta obra la actualidad de tales planteamientos. En consonancia con los trabajos mencionados se encuentra el estudio de Ángeles Encinar, en el que se recoge el arte del cuento de M. Baquero desde una perspectiva más general y diacrónica (como indica que fue el acercamiento de este teórico al cuento, «diacrónico y universal»), comparando sus aportaciones con las de otros grandes investigadores como Ingram, E. Anderson Imbert, A. Grandes o J. Cortázar.

Del mismo modo, en el bloque destinado a sus estudios sobre la novela encontramos dos trabajos que abordan las aproximaciones teóricas, críticas e históricas de Baquero desde esta misma perspectiva, tres que presentan sus acercamientos a la obra de determinados autores y uno que se centra en las estructuras novelescas propuestas por el investigador. Entre los dos primeros se encuentra la aproximación de Ana Luisa Baquero a los primeros años de la trayectoria investigadora de Baquero Goyanes (en concreto hasta 1961). En ella, se refleja la inclinación baqueriana por las categorías fundamentales del discurso novelesco, por la voz narrativa, el perspectivismo o la novela contemporánea. De este modo, aparece constatado cómo en esas primeras décadas ya habían fraguado con claridad en él los fundamentos de su pensamiento teórico-crítico. En el otro estudio, Luis Beltrán se sirve de la categoría baqueriana que considera más próxima a la dimensión estética -el tono-, de sus ideas en torno al perspectivismo o los géneros literarios o de su «espíritu sin fronteras» y pequeñas incursiones en el «simbolismo», para demostrar la vigencia y actualidad de Baquero y situarlo -junto con Ortega, Menéndez Pelayo y Bergamín- en los dominios de lo que estima las principales aportaciones a la teoría de la novela en España. Por otra parte, y al igual que Abraham Esteve, Antonio Garrido Domínguez y Vicente Gómez ofrecen una visión del Baquero prologuista, en esta ocasión de la edición de El Escándalo, no sin antes contextualizarla dentro de toda la obra del catedrático murciano. Este prólogo le da pie a ofrecer una panorámica de los principales intereses de Baquero, de su anticipo a las ideas del Formalismo y Estructuralismo en España o de su mencionada por él «obsesión por el perspectivismo». A su vez, Dolores Thion se acerca a los estudios de Pardo Bazán realizados por él, más centrados en la forma de la prosa que en los temas o contenido socio-histórico e ideológico, reivindicando la modernidad e iconoclastia de un investigador que se introdujo en los misterios de una mujer escritora cuando los estudios literarios poseían un sesgado carácter masculino. También en este apartado, Sandra Mendoza se aproxima a la labor de Mariano Baquero en torno a la producción de Francisco Ayala, reflejando cómo una vez más el crítico se mostró conocedor de la crítica realizada hasta el momento, gozó de un lúcido carácter a la hora de analizar dicha obra y expuso su constante 
versatilidad al desarrollar, en ese intento, tanto su faceta crítica como editora. Además, Miguel Ángel Márquez revisa algunas de las conexiones existentes entre la novela breve y la tragedia y constata cómo estos dos géneros independientes pueden ser reinterpretados a la luz de las estructuras novelescas de Baquero Goyanes.

El tercer apartado, destinado a las contribuciones de M. Baquero a la enseñanza de la literatura, se inicia con el trabajo de José Ángel Baños sobre la enseñanza de la lectura en sus lecciones de Bachillerato. En él se expone cómo este crítico ya contaba con tres décadas de investigación sobre la figura del lector antes de que en los años 70 la administración propugnara el contacto directo con el texto y cómo en sus manuales supo adaptarlo al perfil de sus destinatarios. A esto último también hacen referencia Illán Castillo y López Peñaranda en sus respectivos estudios sobre la representación de la música y las artes visuales en su relación con la literatura dentro de estas lecciones. Mientras que Illán Castillo se centra en categorías estéticas como el tiempo y el espacio, en la faceta estructuralista de Baquero o en conceptos como la escala métrica o el leitmotiv (por estar todo ello íntimamente relacionado con la imbricación literatura-música que llevó a cabo el profesor), López Peñaranda se aproxima al concepto de bodegón literario, a la transformación de la pintura en estampas literarias o al enfoque y perspectivismo que para el investigador comparten el cine y la fotografía con la literatura o la arquitectura y escultura con la estructura literaria. No obstante, ambas coinciden en exceder los márgenes de estas lecciones y manifestar cómo estas relaciones interartísticas estuvieron presentes en toda la obra de Baquero. Por último, Escrig Aparicio homenajea el curioso, delicado y finalmente recopilado como libro La educación de la sensibilidad literaria. En este estudio destaca la predilección baqueriana por la «aproximación afectiva» a la obra y desarrolla ciertos principios sobre el arte de enseñar literatura que el catedrático propuso avalados por su propia experiencia docente.

Como cabe percibir y comprobar, son estos diversos y abarcadores estudios un exquisito retrato de la labor del que es ya considerado una de las personalidades más relevantes en los estudios hispánicos sobre la novela y el cuento, y que, sin embargo, se encuentra poco estudiado. Se constituye este libro, así, como el hallazgo de una caracola marina en un viaje cuyo destino es el océano, como un sonido ya registrado, como una parada inexcusable para todos aquellos que asuman el reto de ampliar el horizonte de la teoría de la novela y del cuento. 